\title{
Individualized ranibizumab therapy strategies in year 3 after as-needed treatment for polypoidal choroidal vasculopathy
}

\author{
Taiichi Hikichi
}

\begin{abstract}
Background: To investigate the third-year results of ranibizumab monotherapy for polypoidal choroidal vasculopathy (PCV) in individualized treatment regimens based on the outcomes during 2 years.

Methods: One hundred seventy-two consecutive eyes of 163 prospective treatment-naiive patients with PCV were treated with three monthly intravitreal ranibizumab injections followed by as-needed reinjections and completed a 2-year follow-up. Treatment regimens during the third year were selected individually based on their outcomes from the following treatment regimens: as-needed injections based on quarterly examinations, as-needed injections based on monthly examinations, a monthly ranibizumab injection schedule, and the treat-and-extend schedule. Visual acuity (VA) and foveal thickness at the end of the third year and the prevalence of discontinuous follow-up examinations during the third year were evaluated.
\end{abstract}

Results: Of 163 patients, 35 (21\%) patients were excluded; nine patients had discontinuous follow-up examinations during the third year. In 128 eyes of 128 patients studied during the third year, the significant improvements in VA and foveal thickness 2 years after the first injection compared to baseline were maintained at the end of the third year. Six (18\%, 6/34) patients treated with as-needed injections based on quarterly examinations had discontinuous follow-up examinations, the prevalence of which differed significantly $(P=0.025)$ from the other groups.

Conclusions: The individualized treatment strategies in the third year based on each patient's outcomes during 2 years maintained the improved VA and avoided discontinuation of follow-up during the third year.

Keywords: Individualized therapy, Polypoidal choroidal vasculopathy, Ranibizumab

\section{Background}

The Seven-Year Observational Update of Macular Degeneration Patients Post-MARINA [1] (the Minimally Classic/Occult Trial of the Anti-VEGF [vascular endothelial growth factor] Antibody Ranibizumab in the Treatment of Neovascular Age-Related Macular Degeneration [AMD])/ANCHOR [2] (the Treatment of Predominantly Classic Choroidal Neovascularization in Age-related Macular Degeneration) and HORIZON [3] (the Open-Label Extension Trial of Ranibizumab for Choroidal Neovascularization Secondary to Age-Related Macular Degeneration) trials [4] was conducted to assess the long-term visual acuity (VA) outcomes and disease status 7 to 8 years after initiation of intensive ranibizumab

Correspondence: taiichi-hikichi@hokkaido.med.or.jp

Ohtsuka Eye Hospital, Kita-16 Nishi-4, Kita-ku, Sapporo 001-0016, Japan
(Lucentis, Genentech Inc., South San Francisco, CA) therapy and evaluate the risk of late visual decline over years 4 to 8 since leaving the HORIZON study [3]. At a mean 7.3 years after initiation of intensive ranibizumab treatment, about one third of patients had a VA of 20/70 or better Snellen equivalent, and almost one quarter had good vision (20/40 or better). However, a third had poor vision (20/200 or worse). In half of patients, the fellow non-study eyes also had wet AMD, and $6 \%$ of patients were legally blind, with 20/200 vision or worse bilaterally. The results suggested that to maintain the VA gain in patients with neovascular AMD treated with ranibizumab, patients may have to be followed more frequently than quarterly or treated more frequently. Recent trials [3-7] have reported that as-needed ranibizumab injections based on monthly examinations could be effective if patients strictly adhered 
to the prespecified objective treatment criteria, which requires intensive long-term follow-up.

A previous study reported that monthly intravitreal injections of ranibizumab for 3 months followed by an as-needed reinjection schedule resulted in continued VA improvement that was maintained throughout 2 years of follow-up in eyes with polypoidal choroidal vasculopathy (PCV) [8]. Although the mean \pm standard deviation (SD) total number of injections during 2 years was $5.6 \pm 1.9$ and the patients visited our clinic monthly according to an as-needed reinjection schedule based on monthly examinations, the numbers of reinjections and the changes in VA varied among patients. Because PCV is a chronic disease and patients must be followed over the long term $[9,10]$, a strict treatment regimen is essential to maintain favorable VA outcomes with ranibizumab therapy and quality of vision and life [11-13]. However, it is difficult to continue strict treatment regimens over the long term. The treatment burden of aggressive as-needed injections includes the injections themselves, monthly visits (required for the optimal efficacy of as-needed injection regimens), ancillary examinations to evaluate the retreatment efficacy, and interpretation of the results based on the retreatment criteria. Further, since the degree of patient satisfaction with the results of ranibizumab treatment and the status of the fellow eye vary, adherence to and motivation to continue ranibizumab treatment likely also vary among patients. The risk of a marked decrease in VA has been reported during discontinuation of follow-up examinations, indicating that regular examinations are warranted and that the major reasons for discontinuation were sustained low VA and lack of apparent treatment response [14].

Thus, at the end of the second year of an as-needed reinjection schedule based on monthly examinations, to avoid losing patients to follow-up, continue treatment, and maintain the VA gains achieved during the 2-year treatment, the treatment schedule for the third year was changed from an as-needed reinjection schedule based on monthly examinations of all patients to treatment schedules based on the clinical course during the 2-year follow-up period in each patient. The current study reports the results after 3 years of ranibizumab therapy, i.e., three monthly injections followed by as-needed reinjections based on monthly examinations for 2 years and an individualized treatment regimen for the third year based on the clinical course during the 2-year follow-up period.

\section{Methods}

One hundred seventy-two consecutive eyes of 163 prospective treatment-naïve Japanese patients with symptomatic PCV who received monthly intravitreal injections of
$0.5 \mathrm{mg}$ of ranibizumab for 3 months followed by a reinjection schedule based on need were followed for 2 years.

PCV was defined as the presence of one or multiple focal areas of hyperfluorescence arising from the choroidal circulation within the first 6 minutes after injection of indocyanine green with or without an associated branching vascular network. Polypoidal lesions are solitary (arbitrarily defined as one or two polyps) or multiple, i.e., arranged in a ring or cluster [15-17]. There were no exclusion criteria regarding the baseline VA or lesion size. Most eyes in the current study were in our previous study [8] that reported the 2-year outcomes of ranibizumab monotherapy for PCV. Reinjections were administered during the third year if any of the following occurred $[7,8]$ : visual loss determined using a decimal VA chart, with fluid at the macula seen on optical coherence tomography (OCT) images; any qualitative changes seen on the OCT images that suggested recurrent fluid in the macula including enlargement of a pigment epithelial detachment; new macular hemorrhages; or persistent fluid in the OCT images 1 month after the previous injection. All criteria were based on comparisons with the previous examination. Since an as-needed injection protocol was much tighter than that used previously and is often referred to as "zero tolerance", [18] any fluid seen on OCT images was added to the usual retreatment criteria. When a reinjection was required, intravitreal ranibizumab was administered on the same day as the examination.

At the end of the second year of ranibizumab therapy, one of the following four treatment schedules was adopted during the third year for each patient after they provided informed consent: 1) as-needed injections based on quarterly examinations were administered if two or fewer reinjections had been administered during the second year, the treated eye was the nondominant eye with 0.1 decimal VA (equivalent to 20/200 Snellen VA) or worse, and the VA of the dominant fellow eye was 0.7 decimal VA (equivalent to about 20/30 Snellen VA) or better; 2) as-needed injections based on monthly examinations were continued even if two or fewer reinjections had been administered during the second year and the patients did not meet the previous criterion; 3 ) if five or more reinjections had been administered during the second year, a monthly ranibizumab injection schedule was adopted that included the dominant eye or the eye with a VA decrease of 0.3 logarithm of the minimum angle of resolution (logMAR) unit converted from the decimal VA or more from the baseline logMAR VA during the 2-year follow-up period of asneeded treatment based on monthly examinations; and 4) the treat-and-extend schedule [19] was adopted if three or four reinjections had been administered during the second year or the patients did not meet the 
third criterion even if five or more reinjections had been administered during the second year.

The institutional review board of Ohtsuka Eye Hospital approved the treatment strategy. The current research followed the tenets of the Declaration of Helsinki. All patients provided informed consent after explanation of the study protocol. Since aflibercept (Eylea, Regeneron, Tarrytown, NY, and Bayer, Berlin, Germany) and bevacizumab (Avastin, Genentech, Inc.) had not yet been approved at the end of the second year of this study in Japan, switching the anti-VEGF agents could not be considered as a treatment strategy for neovascular AMD.

In cases with bilateral disease, the eye treated first with ranibizumab was included in the current study. The VA was measured with the Landolt ring chart. Digital simultaneous fluorescein angiography and indocyanine green angiography images were obtained by scanning laser ophthalmoscopy (Heidelberg Retina Angiograph II, Heidelberg Engineering Inc., Dossenheim, Germany) throughout the study. The foveal thickness was based on the average foveal thickness on the vertical and horizontal scans of OCT (OCT 3000, Zeiss Humphrey Instruments, Dublin, CA or Spectralis, Heidelberg Engineering Inc.). The VA was measured and OCT was performed at every visit during the 3-year follow-up period.

The logMAR unit calculated from the decimal VA was used to analyze the VA. Statistical analysis was performed using SPSS 11.5.1 for Windows software package (SPSS Inc., Chicago, IL). Multiple comparisons were performed by one-way analysis of variance with the Scheffe's $F$ test. $P<0.05$ was considered significant.

\section{Results}

Of 163 prospective treatment-naïve Japanese patients who received ranibizumab therapy for 2 years, 18 patients chose to return to the clinics that referred them to our institute for treatment of PCV at the end of the 2-year treatment period. Eight patients were excluded from the current study, because even though the patients met the criteria of the monthly treatment schedule, they could not return for monthly visits during the third year because of proximity to the clinic, absence of available ophthalmic clinicians, or the treatment schedule for as-needed injections based on quarterly examinations was selected for the third-year treatment. Nine patients had discontinuous follow-up examinations during the third year. Thus, 128 $(79 \%, 128 / 163)$ eyes of 128 patients (mean \pm SD age, $73 \pm$ 8 years; range, $47-89$ years) were studied in the analysis of the clinical outcomes during the third year.

During the third year, 28 eyes received as-needed injections based on quarterly examinations, 61 eyes received asneeded injections based on monthly examinations, 18 eyes received monthly ranibizumab injections, and 21 eyes had a treat-and-extend schedule. Table 1 shows the mean age and the number of ranibizumab injections in each treatment group. Since the study eyes were divided into four groups depending on the number of injections during the second year, the numbers of injections during the second and third years differed significantly $(P=0.01)$ between every two groups.

Table 2 shows the mean $( \pm \mathrm{SD}) \log$ MAR VA at various times after the first injection. In 128 eyes, the VAs at 1,2 , and 3 years after the first injection significantly $(P=0.01$, $P=0.01$, and $P=0.04$, respectively) improved compared to the baseline VA. Although the VA decreased significantly $(P=0.01)$ during the second year, the VA at the end of the second year was maintained at the end of the third year (Figure 1). In eyes treated with as-needed injections based on quarterly examinations during the third year, the baseline VA was the worst among the four groups, but the baseline VA was maintained at the end of the third year. However, the VA 3 years after the first injection decreased significantly $(P=0.01)$ compared to the VA 2 years after the first injection. In eyes treated with as-needed injections based on monthly examinations during the third year, the VAs at 1, 2, and 3 years after the first injection improved significantly ( $P=0.01$, for all comparisons) compared with the baseline VA. Although the VA decreased significantly $(P=0.01)$ during the second year, no difference was found in the VA between 2 and 3 years after the first injection. In eyes receiving monthly injections, the baseline VA was relatively good, but the VA 1 year after the first injection improved significantly $(P=0.03)$ compared

Table 1 The mean ( \pm standard deviation) age and number of ranibizumab injections in each treatment schedule group

\begin{tabular}{|c|c|c|c|c|}
\hline \multirow{2}{*}{$\begin{array}{l}\text { Treatment schedule } \\
\text { During the third year }\end{array}$} & \multirow[b]{2}{*}{ Age } & \multicolumn{3}{|l|}{ No. injections } \\
\hline & & $\begin{array}{l}\text { During the first } \\
\text { year including } \\
\text { three monthly } \\
\text { injections }\end{array}$ & $\begin{array}{l}\text { During } \\
\text { the } \\
\text { second } \\
\text { year }\end{array}$ & $\begin{array}{l}\text { During } \\
\text { the } \\
\text { third } \\
\text { year }\end{array}$ \\
\hline All eyes $(n=128)$ & $73(8)$ & $4.2(1.3)$ & $2.2(1.9)$ & $3.9(4.1)$ \\
\hline \multicolumn{5}{|l|}{$\begin{array}{l}\text { As-needed-injections } \\
\text { determined by } \\
\text { quarterly examination } \\
\text { schedule }\end{array}$} \\
\hline$(n=28)$ & $73(8)$ & $4.3(1.6)$ & $0.6(0.9)$ & $1.0(0.9)$ \\
\hline \multicolumn{5}{|l|}{$\begin{array}{l}\text { As-needed injections } \\
\text { determined by monthly } \\
\text { examinations schedule }\end{array}$} \\
\hline$(n=61)$ & $71(8)$ & $4.0(1.2)$ & $1.5(0.9)$ & $1.8(1.1)$ \\
\hline $\begin{array}{l}\text { Monthly injection } \\
\text { schedule }(n=18)\end{array}$ & $75(8)$ & $4.3(1.8)$ & $5.5(0.8)$ & $11.4(0.7)$ \\
\hline $\begin{array}{l}\text { Treat-and-extend } \\
\text { schedule }(n=21)\end{array}$ & $78(7)$ & $4.6(1.0)$ & $3.8(0.6)$ & $6.4(2.4)$ \\
\hline
\end{tabular}


Table 2 The mean ( \pm standard deviation) visual acuity of the logarithm of the minimum angle of resolution at various points after the first injection in each treatment schedule group

\begin{tabular}{|c|c|c|c|c|}
\hline \multicolumn{5}{|l|}{ Treatment schedule } \\
\hline During the third year & Baseline & 1 year & 2 years & 3 years \\
\hline All eyes $(n=128)$ & $0.61(0.51)$ & $0.43(0.43)$ & $0.50(0.42)$ & $0.52(0.47)$ \\
\hline \multicolumn{5}{|c|}{ As-needed injections determined by quarterly examination schedule } \\
\hline$(n=28)$ & $0.98(0.58)$ & $0.89(0.46)$ & $0.93(0.45)$ & $1.12(0.49)$ \\
\hline \multicolumn{5}{|c|}{ As-needed injections determined by monthly examination schedule } \\
\hline$(n=61)$ & $0.48(0.49)$ & $0.23(0.30)$ & $0.30(0.32)$ & $0.30(0.30)$ \\
\hline Monthly injections schedule $(n=18)$ & $0.34(0.08)$ & $0.21(0.18)$ & $0.38(0.17)$ & $0.35(0.12)$ \\
\hline Treat-and-extend schedule $(n=21)$ & $0.72(0.38)$ & $0.55(0.27)$ & $0.63(0.26)$ & $0.52(0.22)$ \\
\hline
\end{tabular}

with the baseline VA. Although the VA decreased significantly $(P=0.01)$ during the second year, no difference was found in the VA between years 2 and 3 after the first injection and the monthly injection maintained the VA during the third year (Figure 1). In eyes on the treat-and-extend schedule, the VA at 1 year after the first injection improved significantly $(P=0.03)$ compared with the baseline VA. The treat-and-extend treatment during the third year significantly $(P=0.01)$ improved the VA compared to the VA after the second year, which was significantly decreased $(P=0.02)$ during the second year with asneeded injections based on monthly examinations.

Table 3 shows the mean $( \pm$ SD) foveal thicknesses at various times after the primary injection. In the 128 eyes and all four treatment groups during the third year, the foveal thicknesses at 1,2 , and 3 years after the first

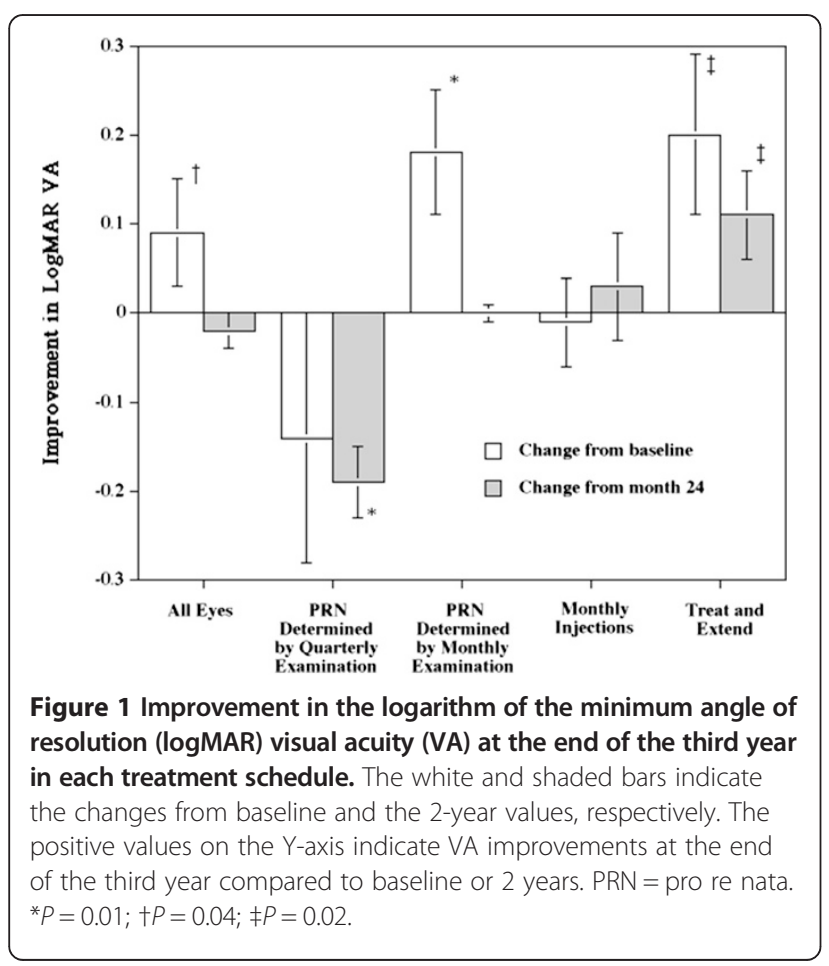

injection were significantly $(P=0.01$, for all comparisons) thinner compared to baseline. No apparent differences were seen in the foveal thicknesses between years 2 and 3 in each treatment group, except that the mean foveal thickness at 3 years was significantly thicker compared to that at 2 years in the group treated with asneeded injections based on quarterly examinations and thinner compared to that at 2 years in the group treated with monthly injections ( $P=0.01$ and $P=0.04$, respectively) (Figure 2).

At the beginning of the third year, 137 patients participated in this study, but nine patients discontinued follow-up examinations during the third year. Thus, 93\% $(128 / 137)$ of patients continued the third-year examinations. Of the nine eyes, six $(18 \%, 6 / 34)$ eyes were treated with as-needed injections based on quarterly examinations, two $(3 \%, 2 / 63)$ eyes were treated with as-needed injections based on monthly examinations, and one (5\%, $1 / 22$ ) eye was treated with the treat-and-extend schedule. The numbers of the patients who had discontinuous follow-up examinations differed significantly $(P=0.04)$ among the groups.

No endophthalmitis, uveitis, lens damage, or prolonged intraocular pressure elevations occurred. Ten eyes underwent cataract surgery during the third year. In three eyes, the presence of minute amounts of vitreous hemorrhage was thought to be associated with the injection site at the uvea but spontaneously resolved within a few days without medication.

\section{Discussion}

In this study, the treatment schedule during the third year in each patient was based on the 2-year results with as-needed injections, monthly examinations, and the VA of the fellow eye. The improved VA in the 128 study eyes at the end of the second year compared to the baseline VA was maintained at the end of the third year. Ninety-three percent of the patients who participated in this study could have continued the follow-up examinations during the third year. 
Table 3 The mean ( \pm standard deviation) foveal thickness $(\mu \mathrm{m})$ at various points after the first injection in each treatment schedule group

\begin{tabular}{|c|c|c|c|c|}
\hline \multicolumn{5}{|l|}{ Treatment schedule } \\
\hline During the third year & Baseline & 1 year & 2 years & 3 years \\
\hline All eyes $(n=128)$ & $338(127)$ & $206(69)$ & $212(62)$ & $212(55)$ \\
\hline \multicolumn{5}{|c|}{ As-needed injections determined by quarterly examination schedule } \\
\hline$(n=28)$ & $349(154)$ & $206(60)$ & $190(39)$ & $216(41)$ \\
\hline \multicolumn{5}{|c|}{ As-needed injections determined by monthly examination schedule } \\
\hline$(n=61)$ & $303(120)$ & $201(73)$ & $200(65)$ & $198(53)$ \\
\hline Monthly injection schedule $(n=18)$ & $380(122)$ & $214(72)$ & $255(49)$ & $231(48)$ \\
\hline Treat-and-extend schedule $(n=21)$ & $377(73)$ & $213(70)$ & $239(68)$ & 225 \\
\hline
\end{tabular}

Since PCV is a chronic disorder $[9,10]$, a choroidal branching vascular network remains after anti-VEGF therapy even when combined with photodynamic therapy $[8,11-13,20]$, which can result in recurrent polypoidal lesions, and clinical examinations are necessary for the patients' lifetimes. Because the fundus findings and natural histories vary in eyes with $\operatorname{PCV}[9,10]$, the numbers of required injections during the second year also varied among eyes with PCV (Table 1). Furthermore, the VAs at the end of the second year varied among the treated eyes and the VAs of the fellow eyes probably differed in each patient. Retina specialists who treat patients with AMD must maintain the patients' activities of daily living (ADL) while considering the treatment outcomes and burden and medical expenses each patient pays [21]. Thus, at the end of 2 years of

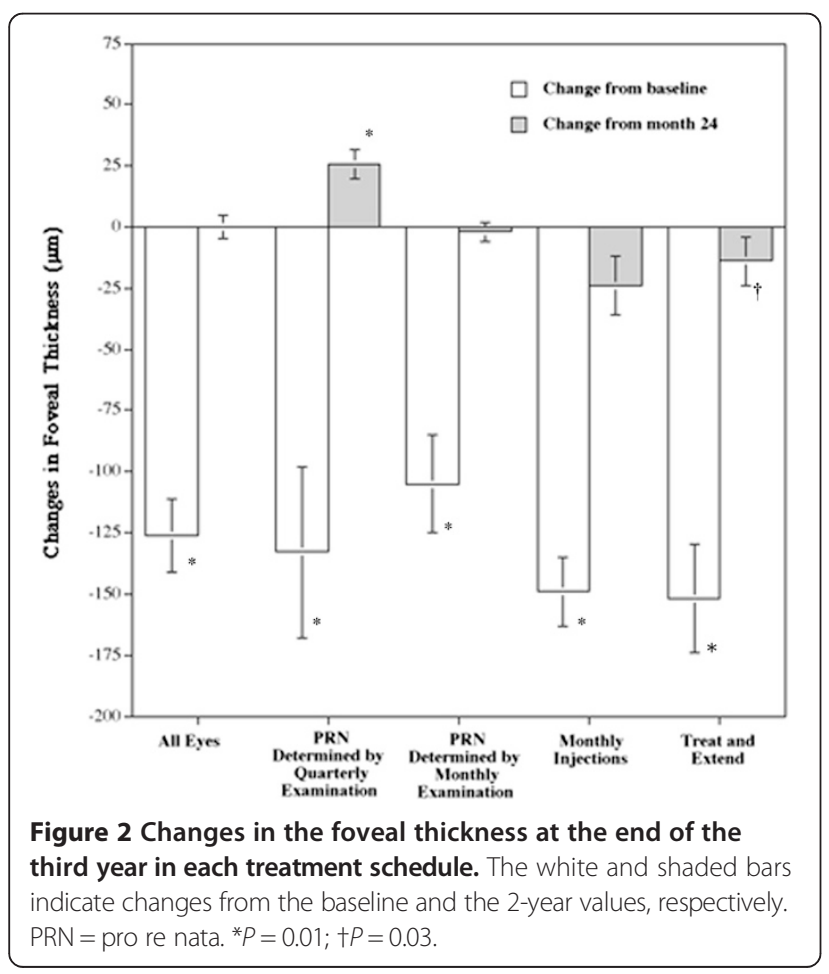

ranibizumab therapy, the treatment regimen in the third year in eyes with PCV was changed from as-needed injections based on monthly examinations to individualized treatment strategies according to each patient's clinical course during the 2-year follow-up period.

In eyes treated with as-needed injections based on monthly examinations, the monthly injection schedule, and the treat-and-extend schedule in the third year, VAs decreased significantly during the second year, but individualized treatment strategies during the third year could avoid the decreased VA. In eyes treated with the treat-and-extend schedule, VA improved significantly during the third year. On the contrary, in eyes treated with as-needed injections based on quarterly examinations, VA decreased significantly during the third year. The outcomes of the four treatment strategies during the third year in the current study showed that 1) asneeded injections based on quarterly examinations resulted in poor visual outcomes, 2) as-needed injections based on monthly examinations maintained the vision of good responders during the 2-year treatment with asneeded injections based on monthly examinations, 3) monthly injections maintained the vision of poor responders during the 2-year treatment with as-needed injections based on monthly examinations, and 4) the treat-and-extend schedule significantly improved the vision of the moderate responders during the 2-year treatment with as-needed injections based on monthly examinations. Recent studies [3,5-7,22,23] have found that strict treatment schedules are needed to obtain the optimal effect of ranibizumab treatment over the long term. Proactive treatment strategies such as monthly injections and a treat-and-extend schedule, which require frequent reinjections compared to as-needed injections based on monthly examinations, may be considered in eyes in which the outcomes of as-needed injections based on monthly examinations were unfavorable.

The goal of this study was that patients continue to be treated and follow the treatment schedule and that optimal visual outcomes are maintained. Since only nine 
(7\%) of 137 eyes had discontinuous follow-up examinations during the third year, the treatment strategy in this study could avoid losing patients to follow-up and continue treatment. Previously published data [24] from the MARINA [2] and ANCHOR [1] trials showed that the 25-item National Eye Institute Visual Function Questionnaire scores improved whether patients were treated in the better or worse eyes, but there was difficulty reaching a clinically meaningful range [25-27] in the worse-seeing eyes compared to the better-seeing eyes. Maintaining treatment compliance and avoiding interruptions in follow-up visits, consideration of the VA of the fellow eye should be necessary to select the treatment strategy. Furthermore, when dominant eyes are treated and the fellow eyes have more severe visual loss, even the temporary VA loss caused by the recurrent exudative changes should affect the ability of patients to perform their ADLs. Such patients want to avoid VA fluctuations and may reject the as-needed injection schedule. Thus, a monthly injection schedule was selected for those patients in the current study.

At the start of the third year, the disadvantage associated with quarterly examinations was anticipated and this concern was shared with the patients and families. When the treatment criteria with quarterly examinations were considered, it was believed that even if the VA decreased during the third year, the disruption of the ADLs would be minimal. The mean VA increased from baseline to month 12 in the quarterly dosing groups in the EXCITE study [28] by 4.0 letters of the Early Treatment of Diabetic Retinopathy Study (ETDRS) chart in the $0.3 \mathrm{mg}$ of ranibizumab quarterly group and 2.8 letters in the 0.5-mg quarterly group, whereas in the PIER study [29] that compared the efficacy of quarterly dosing of ranibizumab with sham treatment, although superior to sham treatment, the VA decreased over the 12-month study period to -1.6 letters in the $0.3-\mathrm{mg}$ quarterly and -0.2 letter in the $0.5-\mathrm{mg}$ quarterly groups. In the current study, the baseline VA was not maintained in eyes treated with as-needed injections based on quarterly examinations. Those eyes responded poorly to as-needed injections based on monthly examinations during 2 years.

In the current study, three (2\%) of 128 eyes had minute amounts of vitreous hemorrhage after the injection during the 3-year follow-up. Since no new hemorrhage caused by PCV lesions was observed, the vitreous hemorrhage was suggested to be associated with the injection site in the uvea. In the 2-year results from the MARINA [1] and ANCHOR [2] studies, the incidence of vitreous hemorrhage was reported to be about $2 \%$.

Since progression of retinal pigment epithelium (RPE) atrophy is common in the natural history of PCV $[9,10]$ and photodynamic therapy (PDT) [30,31], progression of RPE damage during the long-term follow-up period of therapy in eyes with PCV may result in deteriorated visual function. Thus, in the current study, PDT was not considered as a treatment strategy for PCV during the third year.

A limitation of the current study was that about $21 \%$ of the eyes of prospective treatment-naïve Japanese patients who received ranibizumab therapy for 2 years could not participate in this study. This large number of excluded patients may have introduced bias into the outcomes, but this is a scenario in an ordinary clinic. Another limitation was that only ranibizumab was available to treat neovascular AMD in Japan during the current study. Recently, other anti-VEGF agents have been used to treat neovascular AMD. Switching from ranibizumab to another anti-VEGF agent may be an option for longterm follow-up [32]. Furthermore, the results of each treatment schedule during the third year were not simply compared, because the baseline VA levels and responses to ranibizumab during the 2-year treatment differed among the groups. Thus, the results of this study could not confirm which treatment schedule was most effective.

\section{Conclusions}

Despite the limitations, the potential to prevent VA deterioration cannot be ignored, considering the current encouraging long-term treatment outcomes. The improved VA at the end of the second year compared to baseline can be maintained for the third year in patients with PCV treated with ranibizumab. PCV is a chronic disorder and the current findings indicated that the need for anti-VEGF treatment continues in patients with PCV. Since discontinuation of the follow-up will result in decreased VA, close follow-up should be warranted [14]. However, since the degree of patient satisfaction with the results of ranibizumab treatment and the status of the fellow eye vary, adherence to and motivation to continue ranibizumab treatment likely also vary among patients, and a uniform treatment strategy seems to be difficult to continue during long-term follow-up in all patients. Thus, individualized treatment strategies based on each patient's situations should be necessary to not interrupt follow-up. The current study indicated that individualized treatment strategies based on each patient's clinical course during 2 years maintained the improved VA during the third year. Additional studies are warranted to establish a reasonable treatment schedule for patients with PCV who must be followed for the remainder of their lives.

Competing interests

Dr. Hikichi has received lecture fees from Novartis Pharma K.K., Bayer Yakuhin Ltd., Santen Pharmaceutical Co. Ltd, Kowa Pharmaceutical Co. Ltd, Abbott Japan Ltd., Otsuka Pharmaceutical Co. Ltd., and Senjyu Pharmaceutical Co. Ltd. There are no non-financial competing interests. 


\section{Author's contributions}

Since this is a single author's article, TH carried out all of the stages of the study and manuscript preparation.

\section{Acknowledgements}

Publication of this article was not supported by grants.

Received: 6 January 2015 Accepted: 28 March 2015 Published online: 10 April 2015

\section{References}

1. Brown DM, Kaiser PK, Michels M, Soubrane G, Heier JS, Kim RY, et al. Ranibizumab versus verteporfin for neovascular age-related macular degeneration. N Engl J Med. 2006:355:1432-44.

2. Rosenfeld PJ, Brown DM, Heier JS, Boyer DS, Kaiser PK, Chung CY, et al. Ranibizumab for neovascular age-related macular degeneration. N Engl J Med. 2006;355:1419-31

3. Singer MA, Awh CC, Sadda AV, Freeman WR, Antoszyk AN, Wong P, et al. HORIZON: an open-label extension trial of ranibizumab for choroidal neovascularization secondary to age-related macular degeneration. Ophthalmology. 2012;199:1175-83.

4. Rofagha S, Bhisitkul RB, Boyer DS, Sadda SR, Zhang K, for the SEVEN-UP Study Group. Seven-year outcomes in ranibizumab-treated patients in ANCHOR, MARINA, and HORIZON. A multicenter cohort study (SEVEN-UP). Ophthalmology. 2013:120:2292-9.

5. Comparison of Age-related Macular Degeneration Treatments Trials (CATT) Research Group Writing Committee. Ranibizumab and bevacizumab for treatment of neovascular age-related macular degeneration. Two-year results. Ophthalmology. 2012;119:1388-98.

6. Chakravarthy U, Harding SP, Roger CA, Downes SM, Lotery AJ, Culliford LA, et al. Alternative treatments to inhibit VEGF in age-related choroidal neovascularisation: 2-year findings of the IVAN randomised controlled trial. Lancet. 2013;382:1258-67.

7. Lalwani GA, Rosenfeld PJ, Fung AE, Dubovy SR, Michels S, Feuer W, et al. A variable-dosing regimen with intravitreal ranibizumab for neovascular age-related macular degeneration: year 2 of the PrONTO study. Am J Ophthalmol. 2009;148:43-58

8. Hikichi T, Higuchi M, Matsushita T, Kosaka S, Matsushita R, Takami K, et al Results of 2 years of treatment with as-needed ranibizumab reinjection for polypoidal choroidal vasculopathy. Br J Ophthalmol. 2013;97:617-21.

9. Uyama M, Wada M, Nagai Y, Matsubara T, Matsunaga H, Fukushima I, et al. Polypoidal choroidal vasculopathy: natural history. Am J Ophthalmol. 2002;133:639-48.

10. Sho K, Takahashi K, Yamada H, Wada M, Nagai Y, Otsuji T, et al. Polypoidal choroidal vasculopathy, incidence, demographic features, and clinical characteristics. Arch Ophthalmol. 2003:121:1392-6.

11. Inoue M, Arakawa A, Yamane S, Kadonosono K. Long-term outcome of intravitreal ranibizumab treatment, compared with photodynamic therapy, in patients with polypoidal choroidal vasculopathy. Eye (Lond). 2013:27:1013-21.

12. Kang HM, Koh HJ. Long-term visual outcome and prognostic factors after intravitreal ranibizumab injections for polypoidal choroidal vasculopathy. Am J Ophthalmol. 2013:156:652-60.

13. Jeon S, Lee WK, Kim KS. Adjusted retreatment of polypoidal choroidal vasculopathy after combination therapy. Results at 3 years. Retina. 2013;33:1193-200.

14. Rasmussen A, Bloch SB, Fuchs J, Hansen LH, Larsen M, Lacour M, et al. A 4-year longitudinal study of 555 patients treated with ranibizumab for neovascular age-related macular degeneration. Ophthalmology. 2013;120:2630-6.

15. Lim TH, Laude A, Tan CS. Polypoidal choroidal vasculopathy: an angiographic discussion. Eye (Lond). 2010;24:483-90.

16. Koh AHC, on behalf of the expert PCV panel, Chen $\amalg$, Chen SJ, Chen Y, Giridhar A, et al. Polypoidal choroidal vasculopathy. Evidence-based guidelines for clinical diagnosis and treatment. Retina. 2013:33:686-716.

17. Japanese Study Group of Polypoidal Choroidal Vasculopathy. Criteria for diagnosis of polypoidal choroidal vasculopathy [in Japanese]. Nippon Ganka Gakkai Zasshi. 2005;109:417-27.

18. Schmidt-Erfurth U, Chong V, Loewenstein A, Larsen M, Souied E, Schlingemann $R$, et al. Guidelines for the management of neovascular age-related macular degeneration by the European Society of Retina Specialists (EURETINA). Br J Ophthalmol. 2014;98:1144-67.
19. Gupta OP, Shienbaum G, Patel AH, Fecarotta C, Kaiser RS, Regillo CD. A treat and extend regimen using ranibizumab for neovascular age-related macular degeneration. Clinical and economic impact. Ophthalmology. 2010;117:2134-40.

20. Hikichi T, Ohtsuka H, Higuchi M, Matsushita T, Ariga H, Kosaka S, et al. Factors predictive of visual acuity outcomes 1 year after photodynamic therapy in Japanese patients with polypoidal choroidal vasculopathy. Retina. 2011;31:857-65.

21. Haller JA. Current anti-vascular endothelial growth factor dosing regimens Benefits and burden. Ophthalmology. 2013;120:53-7.

22. Lanzetta $P$, Mitchell $P$, Wolf S, Veritti D. Different antivascular endothelia growth factor treatments and regimens and their outcomes in neovascular age-related macular degeneration: a literature review. Br J Ophthalmol. 2013;97:1497-507.

23. Mitchell P, Korobelnik J-F, Lanzetta P, Holz FG, Prünte C, Schmidt-Erfurth U, et al. Ranibizumab (Lucentis) in neovascular age-related macular degeneration: evidence from clinical trials. Br J Ophthalmol. 2010;94:2-13.

24. Bressler NM, Chang TS, Suner IJ, Fine JT, Dolan CM, Ward J, et al. Vision-related function after ranibizumab treatment by better- or worse-seeing eye. Clinical trial results from MARINA and ANCHOR. Ophthalmology. 2010;117:747-56.

25. Miskala PH, Hawkins BS, Mangione CM, Bass EB, Bressler NM, Dong LM, et al. Responsiveness of the National Eye Institute Visual Function Questionnaire to changes in visual acuity: findings in patients with subfoveal choroidal neovascularization-SST report no. 1. Arch Ophthalmol. 2003;121:531-9.

26. Lindblad AS, Clemons TE, Age-Related Eye Disease Study Research Group. Responsiveness of the National Eye Institute Visual Function Questionnaire to progression to advanced age-related macular degeneration, vision loss, and lens opacity: AREDS report no. 14. Arch Ophthalmol. 2005:123:1207-14.

27. Submacular Surgery Trials Research Group. Evaluation of minimum clinically meaningful changes in scores on the National Eye Institute Visual Function Questionnaire (NEI-VFQ) SST report number 19. Ophthalmic Epidemiol. 2007;14:205-15.

28. Schmidt-Erfurth U, Eldem B, Guymer R, Korobelnik JF, Schlingemann RO, Axer-Siegel $R$, et al. Efficacy and safety of monthly versus quarterly ranibizumab treatment in neovascular age-related macular degeneration: the EXCITE study. Ophthalmology. 2011;118:831-9.

29. Regillo CD, Brown DM, Abraham P, Yue H, lanchulev T, Schneider S, et al. Randomized, double-masked, sham-controlled trial of ranibizumab for neovascular age-related macular degeneration: PIER study year 1. Am J Ophthalmol. 2008;145:239-48.

30. Dewi NA, Yuzawa M, Tochigi K, Kawamura A, Mori R. Effects of photodynamic therapy on the choriocapillaris and retinal pigment epithelium in the irradiated area. Jpn J Ophthalmol. 2008;52:277-81.

31. Oishi A, Kojima H, Mandai M, Honda S, Matsuoka T, Oh H, et al. Comparison of the effect of ranibizumab and verteporfin for polypoidal choroida vasculopathy: 12-month LAPTOP study results. Am J Ophthalmol. 2013;156:644-51.

32. Schachat AP. Switching anti-vascular endothelial growth factor therapy for neovascular age-related macular degeneration [Editorial]. Am J Ophthalmol. 2013;156:1-2.

\section{Submit your next manuscript to BioMed Central and take full advantage of:}

- Convenient online submission

- Thorough peer review

- No space constraints or color figure charges

- Immediate publication on acceptance

- Inclusion in PubMed, CAS, Scopus and Google Scholar

- Research which is freely available for redistribution 